\title{
Adenine nucleotide-mediated regulation of hepatic PTP1B activity in mouse models of type 2 diabetes
}

\author{
Xiao Yang ${ }^{1} \cdot$ Yang Zhao $^{1} \cdot$ Qi Sun ${ }^{1} \cdot$ Yunxia Yang ${ }^{1} \cdot$ Yan Gao $^{1} \cdot$ Wenhao Ge $^{1} \cdot$ Junhao Liu $^{1} \cdot \mathrm{Xi} \mathrm{Xu}^{1} \cdot \mathrm{Dan} \mathrm{Weng}^{1} \cdot$ \\ Shiming Wang ${ }^{1} \cdot$ Jianfa Zhang ${ }^{1}$
}

Received: 28 February 2019 / Accepted: 24 June 2019/Published online: 13 August 2019

(C) Springer-Verlag GmbH Germany, part of Springer Nature 2019

\begin{abstract}
Aims/hypothesis Plasma 5'-AMP (pAMP) is elevated in mouse models of type 2 diabetes. However, the metabolic regulatory role of adenine nucleotides in type 2 diabetes remains unclear.

Methods Adenine nucleotides and their metabolites in plasma and liver were examined by HPLC. ${ }^{1} \mathrm{H}$ NMR-based metabolomics analysis was performed to explore the changes of metabolites in mouse models of type 2 diabetes. $\mathrm{Na}^{+} / \mathrm{K}^{+} \mathrm{ATPase}$ and Na $\mathrm{Na}^{+}$ exchanger activity were measured in response to adenine nucleotide metabolites. Human recombinant protein tyrosine phosphatase 1B (PTP1B) was used for enzyme kinetic assays. Protein binding assays were performed with microscale thermophoresis. The intracellular $\mathrm{pH}$ of hepatocyte AML12 cell lines was measured using the BCECF-AM method. We also analysed pAMP levels in participants with type 2 diabetes.

Results Elevation of pAMP was a universal phenomenon in all mouse models of type 2 diabetes including $d b / d b$ vs lean mice $(13.9 \pm 2.3 \mu \mathrm{mol} / 1 \mathrm{vs} 3.7 \pm 0.9 \mu \mathrm{mol} / 1 ; p<0.01), o b / o b$ vs lean mice $(9.1 \pm 2.0 \mu \mathrm{mol} / 1 \mathrm{vs} 3.9 \pm 1.2 \mu \mathrm{mol} / \mathrm{l} ; p<0.01)$ and high-fat $\mathrm{diet} / \mathrm{streptozotocin-induced} \mathrm{vs} \mathrm{wild-type} \mathrm{mice}(6.6 \pm 1.5 \mu \mathrm{mol} / 1 \mathrm{vs} 4.1 \pm 0.9 \mu \mathrm{mol} / 1 ; p<0.05)$; this elevation was required for the occurrence of hyperglycaemia in obese mice. ${ }^{1} \mathrm{H}$ NMR-based metabolomics study following HPLC analysis revealed that the metabolite profile in wild-type mice treated with 5'-AMP was similar to that in $d b / d b$ diabetic mice, especially the accumulation of a large quantity of ATP and its metabolites. The glucose-lowering drug metformin reduced the severity of hyperglycaemia both in 5'-AMP-induced wild-type mice and $d b / d b$ mice. Metformin decreased the accumulation of liver ATP but not its metabolites in these hyperglycaemic mice. ATP and metformin reciprocally change cellular pH homeostasis in liver, causing opposite shifts in liver activity of PTP1B, a key negative regulator of insulin signalling. Furthermore, pAMP levels were also elevated in individuals with type 2 diabetes $(45.2 \pm 22.7 \mathrm{nmol} / \mathrm{l}$ vs $3.1 \pm 1.9 \mathrm{nmol} / \mathrm{l} ; p<0.01)$.

Conclusions/interpretation These results reveal an emerging role for adenine nucleotide in the regulation of hyperglycaemia and provide a potential therapeutic target in obesity and type 2 diabetes.
\end{abstract}

Keywords ATP $\cdot$ Hyperglycaemia $\cdot$ Metformin $\cdot$ Obesity $\cdot \mathrm{pH}_{\mathrm{i}} \cdot \mathrm{PTP} 1 \mathrm{~B}$

\section{Abbreviations \\ AMPK AMP-activated protein kinase}

Xiao Yang, Yang Zhao and Qi Sun contributed equally to this work.

Electronic supplementary material The online version of this article (https://doi.org/10.1007/s00125-019-04971-1) contains peer-reviewed but unedited supplementary material, which is available to authorised users.

Jianfa Zhang

jfzhang@mail.njust.edu.cn

1 Center for Molecular Metabolism, Nanjing University of Science \& Technology, 200 Xiaolingwei, Nanjing 210094, China
ANM Adenine nucleotide metabolite

BCECF-AM (2',7'-Bis-[carboxyethyl]-5-[and-6]carboxyfluorescein)-tetraacetoxymethyl ester

G6Pase Glucose-6-phosphatase

HFD High-fat diet

MST Microscale thermophoresis

OCT1 Organic cation transporter-1

pAMP Plasma 5'-AMP

PEG-ADA Polyethylene glycol-modified adenosine deaminase

$\mathrm{pH}_{\mathrm{i}} \quad$ Intracellular $\mathrm{pH}$

PTP1B Protein tyrosine phosphatase 1B

STZ Streptozotocin 


\section{Research in context}

\section{What is already known about this subject?}

- Plasma $5^{\prime}-A M P($ PAMP) is elevated in the $d b / d b$ mouse model of diabetes

- The injection of 5'-AMP causes hyperglycaemia in wild-type mice

- Protein tyrosine phosphatase 1B (PTP1B) negatively regulates insulin receptor phosphorylation

What is the key question?

- How do adenine nucleotides induce hyperglycaemia in type 2 diabetes?

What are the new findings?

- The elevation of pAMP was required for the occurrence of hyperglycaemia in type 2 diabetes in mouse models and in humans

- Adenine nucleotide metabolites inhibited $\mathrm{Na}^{+} / \mathrm{K}^{+}$ATPase and $\mathrm{Na}^{+} / \mathrm{H}^{+}$exchanger activity

- ATP accumulation changed the cellular $\mathrm{pH}$ homeostasis in the liver, directly stimulating PTP1B activity

How might this impact on clinical practice in the foreseeable future?

- Adenine nucleotide-related intracellular $\mathrm{pH}$ is a potential therapeutic target in obesity and type 2 diabetes

\section{Introduction}

Endogenous glucose production, including hepatic glycogenolysis and gluconeogenesis, is essential for survival during starvation [1]. On the other hand, excessive glucose production contributes to hyperglycaemia in individuals with diabetes [2]. In type 2 diabetes, hyperglycaemia occurs due to insulin insensitivity in main metabolic organs such as liver and skeletal muscle [3]. Obesity is a major risk factor for type 2 diabetes [4]. Mice deficient in leptin and leptin receptors $(o b /$ $o b$ and $d b / d b$ ) exhibit severe, spontaneous, early-onset obesity, with a body weight three times that of wild-type mice [5], and display type 2 diabetes-like characteristics such as insulin insensitivity, glucose intolerance and hyperinsulinaemia [6]. Both $d b / d b$ and $o b / o b$ mice develop hyperglycaemia after the age of 4 weeks [7, 8]. However, with increasing age, blood glucose levels of $o b / o b$ mice become nearly normal even in the presence of obesity and severe insulin resistance $[8,9]$. Similarly, most high-fat diet (HFD)-induced obese mice maintain non-diabetic glucose levels and present insulin resistance only [10]. In humans, although most people who develop type 2 diabetes are overweight or obese, most obese individuals do not become diabetic even though they present with a high degree of insulin resistance [4].

The failure of pancreatic beta cells to compensate for insulin resistance is thought to release the suppression of gluconeogenesis in the liver and cause hyperglycaemia [11]. However, it is not possible to determine separately the effect of hyperglycaemia and dyslipidaemia on beta cell differentiation status in diabetic mice or in pathological samples from human donors with diabetes [12]. Whether additional factors are acquired secondary to changes in the metabolic milieu associated with the progression to type 2 diabetes remains elusive. It is well known that insulin receptor tyrosine kinase is directly involved in intracellular insulin signalling transduction [13] and that protein tyrosine phosphatase 1B (PTP1B) negatively regulates insulin receptor phosphorylation [14]. It has been observed that the activity of insulin receptor tyrosine kinase does not change in $d b / d b$ diabetic mice [15]. Inhibition of PTP1B is demonstrated to improve insulin sensitivity in obese and insulin-resistant $o b / o b$ mice and reduce the hyperglycaemia in obese $d b / d b$ mice [16].

Metformin is used extensively to treat type 2 diabetes. It acts through multiple mechanisms such as increasing phosphorylation of insulin receptors, stimulating translocation of GLUT4 to the cell membrane, decreasing gluconeogenesis in hepatocytes and activation of AMP-activated protein kinase (AMPK) [17-20]. Other research indicates metformin inhibits the respiratory chain that restrains hepatic gluconeogenesis [21].

Our previous observation indicates that plasma 5'-AMP (pAMP) was elevated in plasma of obese $d b / d b$ diabetic mice and that exogenous 5 '-AMP caused hyperglycaemia-like type 2 diabetes in wild-type mice [22]. We are interested in understanding the role of adenine nucleotides in metabolic regulation, insulin resistance and hyperglycaemia occurring in type 2 diabetes. In this study, we have investigated the role of adenine nucleotides in regulating the activity of PTP1B in 
type 2 diabetes. Our studies provide insight into the participation of adenine nucleotides in obese diabetic mice.

\section{Methods}

Animal models Mice were obtained from SLACCAS (Shanghai, China). Male C57BL/6, C57BL/6 ob/ob, C57BL/ $\mathrm{Ks} d b / d b$ mice and their homozygous lean littermates $(+/+)$ were used. To create diet-induced insulin resistance models, 4week-old male C57BL/6 mice were fed an HFD. HFD-fed mice were injected intraperitoneally with streptozotocin (STZ) to induce diabetes. All procedures were approved by the Animal Care and Use Committee at Nanjing University of Science and Technology (NJUST-AC-05-1217). See electronic supplementary material (ESM) Methods for further details.

Injection of 5'-AMP and metformin and ITT Male 8-week-old C57BL/6 mice were injected intraperitoneally with 5'-AMP at 09:00. Metformin hydrochloride was administered by gavage. Mice were killed $1 \mathrm{~h}$ after 5'-AMP treatment. For ITT, mice were fasted and injected intraperitoneally with insulin. See ESM Methods for details.

Tissue and blood sampling Mice were euthanised, blood was collected and then tissues were removed and freeze-clamped in liquid nitrogen. Erythrocytes and plasma were separated. See ESM Methods for further details.

HPLC analysis of nucleotides and metabolites Mouse livers were homogenised using ice-cold $0.4 \mathrm{~mol} / \mathrm{l}$ perchloric acid. Samples were analysed using HPLC (Waters 1525 System; Millipore, Bedford, MA, USA) on a reversed-phase C18 column as described previously [23-25]. Pure nucleotides and metabolites were used to identify the peaks and obtain the calibration curves. Quantification was based on the area under the peaks.

\section{${ }^{1} \mathrm{H}$ NMR-based metabolomics analysis of tissue extraction Tissues were extracted using ice-cold 50\% acetonitrile. The spectra were acquired on a Bruker AV 500-MHz spectrometer (Bruker, Karlsruhe, Germany). The integrated area was nor- malised. Unsupervised principal component analysis methods were performed. According to the integrated areas of metab- olites, the increased or decreased factors were calculated. See ESM Methods for details.}

$\mathrm{Na}^{+} / \mathrm{K}^{+}$ATPase assay for hepatic plasma membrane Liver plasma membrane was prepared as described previously [26]. $\mathrm{Na}^{+} / \mathrm{K}^{+}$ATPase assay was performed as previously described, with modification [27]. The reaction was started by adding ATP. Released inorganic phosphate was measured. $\mathrm{Na}^{+} / \mathrm{K}^{+}$ATPase activity was calculated by comparison with the ATPase activity inhibited by ouabain. See ESM Methods for details.

Quantitative real-time PCR Total RNA from mouse liver was isolated and quantitative real-time PCR was used to determine relative mRNA of mouse Pepck (also known as Pckl) and G6pase (also known as G6pc). See ESM Methods for details; primers are listed in ESM Table 1.

Glucose-6-phosphatase and PEPCK activity measurement Glucose-6-phosphatase (G6Pase) and PEPCK activity were analysed as previously described [28, 29]. See ESM Methods for details.

Treatment of $d b / d b$ mice with polyethylene glycol-modified adenosine deaminase Polyethylene glycol-modified adenosine deaminase (PEG-ADA) was prepared with recombinant adenosine deaminase and mPEG-succinimidyl propionate (mPEG-SPA; Chemgen Pharma, Beijing, China). Obese $d b /$ $d b$ mice were injected with PEG-ADA prior to experiments. See ESM Methods for details.

Preparation of metformin Metformin hydrochloride (20 g) was dissolved in 1 litre of methanol containing $2 \%$ vol./vol. water. The solution was then passed through a column containing anion exchange resin Duolite A101D (Jinjinle Chemical Co., Changsha, China). The column was then rinsed with 1 litre of methanol containing $2 \% \mathrm{vol} . / \mathrm{vol}$. water. The elute solution was evaporated to dryness under reduced pressure at $40^{\circ} \mathrm{C}$ to obtain metformin, which was used immediately.

PTP1B activity and kinetic analysis PTP1B activity in liver extract was determined as described previously, with modification [30]. Liver was homogenised in cold PBS. The supernatant fractions were diluted and reaction was started by adding p-nitrophenyl phosphate. For kinetic analysis, recombinant PTP1B was used. See ESM Methods for details.

Microscale thermophoresis binding analyses Microscale thermophoresis (MST) analysis was performed using the MST device (Monolith NT.115) as described previously with modification [31]. Data were treated with NT analysis software (see ESM Methods for further details).

Intracellular $\mathrm{pH}$ measurement The measurement of intracellular $\mathrm{pH}\left(\mathrm{pH}_{\mathrm{i}}\right)$ was performed as previously described, with modification [32]. AML12 cells were used and stained with Hanks' buffered saline solution (HBSS) solution containing $1 \mu \mathrm{mol} / 1$ (2',7'-bis-[carboxyethyl]-5-[and-6]-carboxyfluorescein)-tetraacetoxymethyl ester (BCECF-AM) for $20 \mathrm{~min}$ at room temperature. Then the cells were perfused with HBSS. $\mathrm{pH}_{\mathrm{i}}$ measurements were performed at $37^{\circ} \mathrm{C}$ using a fluorescence microscope (Nikon, Tokyo, Japan). BCECF 
fluorescence was excited at $490 \mathrm{~nm}$ and $440 \mathrm{~nm}$ and emitted fluorescence was measured at $530 \mathrm{~nm}$. The F490/F440 emission ratio was converted to $\mathrm{pH}$ scale according to the nigericin technique. See ESM Methods for details.

$\mathrm{Na}^{+} / \mathrm{H}^{+}$exchanger activity $\mathrm{Na}^{+} / \mathrm{H}^{+}$exchanger activity was analysed in bicarbonate-free solution. After equilibrating, AML12 cells were acidified by adding propionate. The recovery rate of $\mathrm{pH}_{\mathrm{i}}$ was calculated from data obtained during the initial recovery period. See ESM Methods for details.

Intracellular sodium determination AML12 cells were treated with 5'-AMP. After removal of medium, cells were washed and lysed. Intracellular sodium was estimated using atomic absorption spectrometry. See ESM Methods for details.

Vacuolar-type $\left(\mathrm{H}^{+}\right)$ATPase activity The microsome fraction was prepared from mouse liver by differential centrifugation. Hydrolysis of ATP by microsome was analysed. Released inorganic phosphate was measured. V-ATPase activity was defined as the ATPase activity inhibited by bafilomycin A1. See ESM Methods for details.

Study participants Twenty-five individuals with type 2 diabetes and 21 healthy individuals (control group) were recruited. Blood samples were obtained in the early morning through the Second Hospital of Nanjing. Upon arrival, body mass and height measurements were taken to determine BMI, and blood samples were obtained using venepuncture. All blood samples were obtained after informed consent was obtained from both the diabetic and healthy individuals for their participation in the study. $\mathrm{HbA}_{1 \mathrm{c}}$ was determined with the gold standard ion-exchange method (Tosoh G8 HPLC Analyzer, Tosoh Bioscience, San Francisco, CA, USA). Blood glucose was determined using a OneTouch Ultra blood glucose meter (Life-Scan, Milpitas, CA, USA). Plasma insulin was analysed using the Roche E170 chemiluminescent immunoassay (Roche Diagnostics). Plasma was deproteinised using ice cold $0.4 \mathrm{~mol} / \mathrm{l}$ perchloric acid and then analysed using HPLC. Demographics are shown in Table 1. All procedures were approved by the Institutional Review Board of Nanjing University of Science and Technology.

Statistical analysis Data are presented as means \pm SD. Statistical analysis was performed by Student's $t$ test, oneway ANOVA or two-way ANOVA followed by Tukey's post hoc test. Significance was defined as $p<0.05$.

\section{Results}

Elevated pAMP as a biomarker for type 2 diabetes in mouse models To investigate whether elevated pAMP is an independent event in obese $d b / d b$ diabetic mice, we measured pAMP
Table 1 Participant demographics

\begin{tabular}{lll}
\hline Characteristic & Healthy & Type 2 diabetes \\
\hline$n$ (women/men) & $25(10 / 15)$ & $21(9 / 12)$ \\
Age (years) & $35 \pm 10$ & $40 \pm 11$ \\
Diabetes duration $(<1 /<10 / \geq 10$ years) & - & $3 / 8 / 10$ \\
Body weight $(\mathrm{kg})$ & $63.2 \pm 15.1$ & $78.3 \pm 12.1 * *$ \\
$\mathrm{BMI}\left(\mathrm{kg} / \mathrm{m}^{2}\right)$ & $21.5 \pm 4.8$ & $29.4 \pm 3.7 * *$ \\
$\mathrm{HbA}_{1 \mathrm{c}}(\mathrm{mmol} / \mathrm{mol})$ & - & $64.5 \pm 16.9$ \\
$\mathrm{HbA}_{1 \mathrm{c}}(\%)$ & - & $8.1 \pm 1.5$ \\
\hline
\end{tabular}

Data are mean $\pm \mathrm{SD}$

${ }^{* *} p<0.01$ vs healthy participants (Student's $t$ test)

levels in different mouse models of insulin resistance. In accordance with findings from a previous study, pAMP increased in $d b / d b$ vs lean mice $(13.9 \pm 2.3 \mu \mathrm{mol} / 1$ vs $3.7 \pm$ $0.9 \mu \mathrm{mol} / 1 ; p<0.01$; Fig. 1a). The increase in pAMP was also observed in diabetic $o b / o b$ vs lean mice $(9.1 \pm 2.0 \mu \mathrm{mol} / \mathrm{l}$ vs $3.9 \pm 1.2 \mu \mathrm{mol} / 1 ; p<0.01$; Fig. 1b), HFD-STZ mice vs wildtype mice $(6.6 \pm 1.5 \mu \mathrm{mol} / 1$ vs $4.1 \pm 0.9 \mu \mathrm{mol} / 1 ; p<0.05$; Fig. 1c) and wild-type mice treated with 5'-AMP vs saline (154 mmol/1 NaCl) $(15.1 \pm 2.1 \mu \mathrm{mol} / 1$ vs $4.4 \pm 1.5 \mu \mathrm{mol} / \mathrm{l}$; $p<0.01$; Fig. 1d). Then we analysed the pAMP level in non-diabetic mice with insulin resistance. The results showed no difference in pAMP level between non-diabetic $o b / o b$ and non-diabetic HFD mice compared with control mice (Fig. 1e,f). To understand the role of increased pAMP in metabolic regulation in type 2 diabetes, a survey of ${ }^{1} \mathrm{H}$ NMR-based liver metabolomic data was performed in an obese $d b / d b$ diabetic mouse model for insulin resistance and metabolic disorders (ESM Fig. 1). The plots generated from profiles of extracts of the insulin-sensitive liver in lean and $d b / d b$ obese mice revealed significant separation of metabolites between the two groups (Fig. 1g,h), suggesting that these phenotypes exhibit significantly different metabolic patterns of known and unknown metabolites (ESM Table 2). Interestingly, when we injected 5'-AMP into the wild-type mice, the profiles of liver extracts in these mice exhibited similar metabolomic shifts to those observed in the $d b / d b$ mice (Fig. 1i,j; ESM Table 2). A heat map of the 38 indicated metabolites in at least one of three pair-wise comparisons is shown in Fig. 1k. Pearson $r$ analysis showed strong correlations between biological replicates in each group. Metabolic pathway analysis of the differential metabolite clusters revealed that livers of $5^{\prime}$-AMP-treated and $d b / d b$ mice are enriched in metabolite accumulations including amine acid and nucleotide metabolism. Together, these results suggest that elevated pAMP is a common marker and plays a potential role in hyperglycaemia in mouse models of type 2 diabetes.

The accumulation of liver ATP and adenine nucleotide metabolites is required for hyperglycaemia in obese mice HPLC 

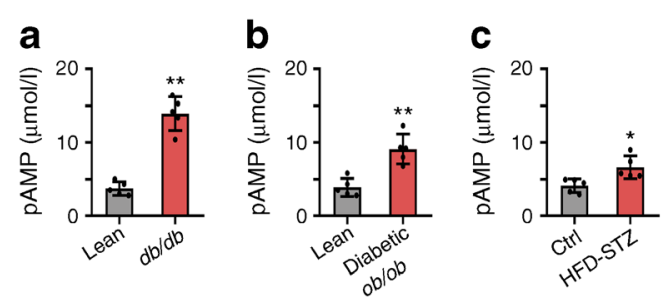
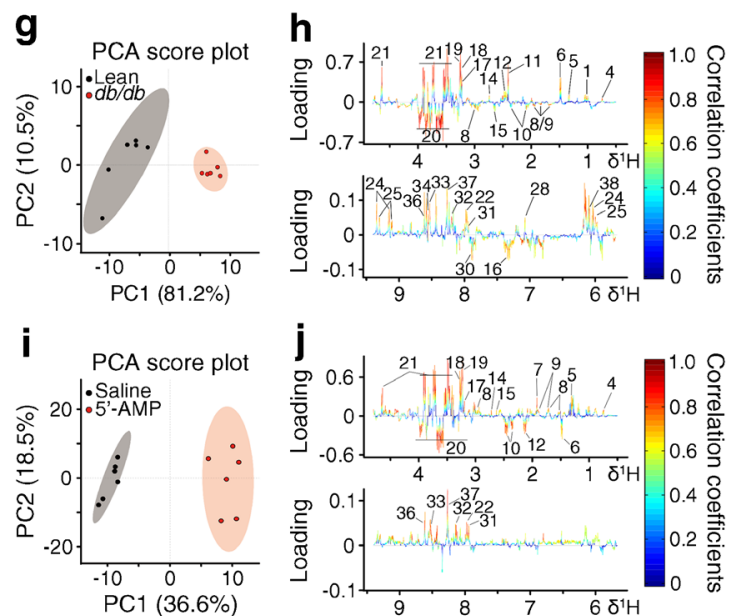
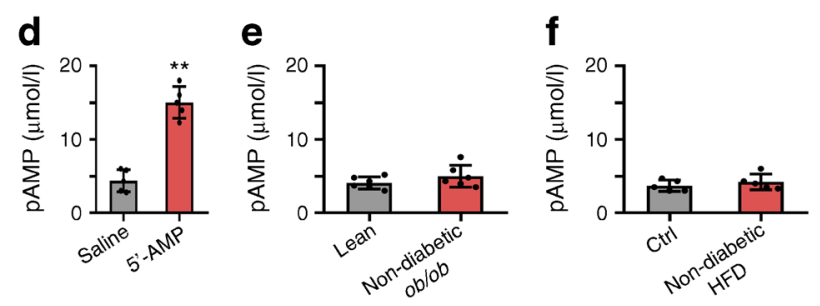

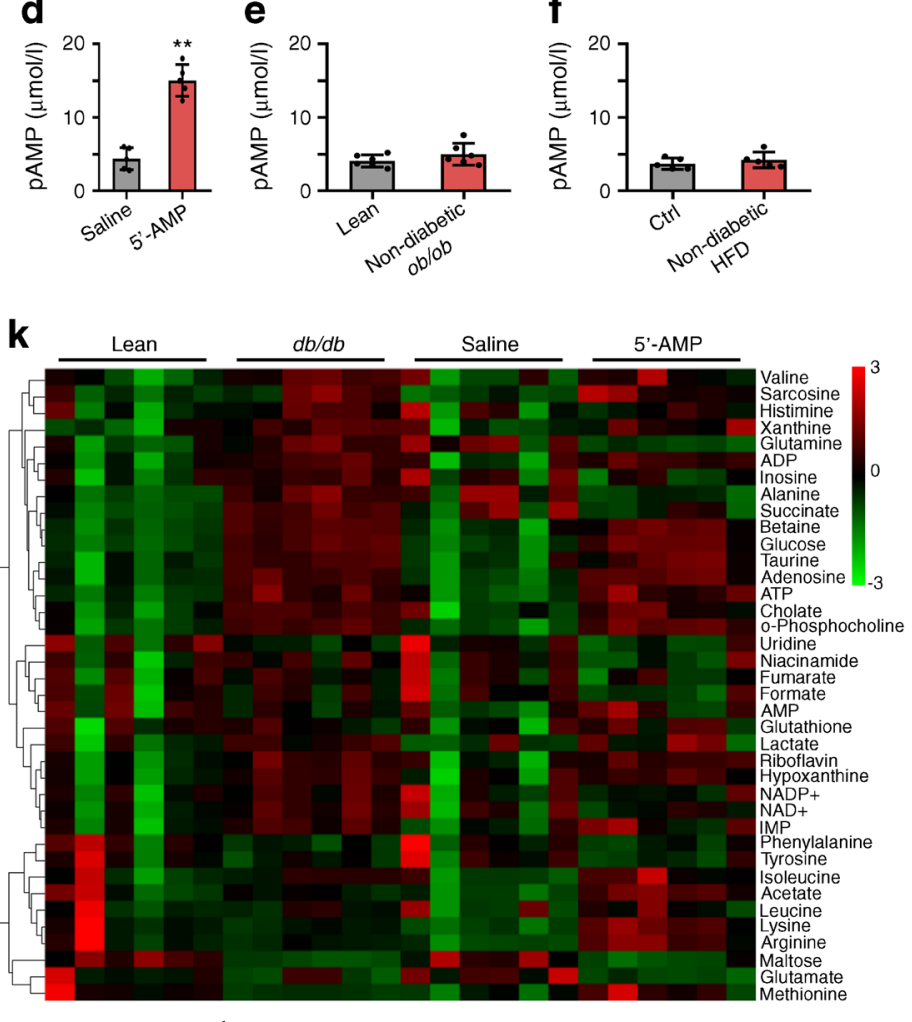

based on ${ }^{1} \mathrm{H}$ NMR data from livers of lean and $d b / d b$ mouse groups (g, h) and the 5'-AMP-treated and saline-treated control groups $(\mathbf{i}, \mathbf{j})$. (k) Heat map of 38 metabolites identified in at least one of three comparisons. In $(\mathbf{g}-\mathbf{k}) n=6$ per group. Refer to ESM Fig. 1 for numbered metabolites in $(\mathbf{h}, \mathbf{j})$. Data are expressed as mean $\pm \mathrm{SD} ; * p<0.05$ and $* * p<0.01 \mathrm{com}-$ pared with the respective control group (Student's $t$ test). Ctrl, control; PCA, principal component analysis; $\mathrm{PC} 1 / 2$, principal components 1 and 2

mice and ATP and ANMs were only elevated in the liver of hyperglycaemic mice. To investigate whether the accumulation of ANMs and ATP contributed to hyperglycaemia, we injected 5'-AMP into the wild-type mice and examined the time course of induction of hyperglycaemia and the changes in liver concentrations of ATP and ANMs. Injection of 5'AMP induced hyperglycaemia in $0.5-1 \mathrm{~h}$ and the blood glucose levels returned to normal after $2 \mathrm{~h}$ (Fig. 2e). HPLC analysis revealed that ANMs and ATP levels in liver increased at $1 \mathrm{~h}$ and returned to baseline levels at $2 \mathrm{~h}$ after 5'-AMP injection (Fig. 2f,g). These observations suggest that the accumulation of ATP and ANMs in liver is required for the occurrence of hyperglycaemia in obese mice. Next, we investigated the potential relationship between cellular ATP and ANMs. Figure $2 \mathrm{~h}-\mathrm{k}$ shows the in vitro effects of ANMs on $\mathrm{Na}^{+} / \mathrm{K}^{+}$ATPase activity in plasma membrane in mouse liver. Adenosine had no effect on $\mathrm{Na}^{+} / \mathrm{K}^{+}$ATPase activity but ANMs such as hypoxanthine, xanthine and uric acid markedly inhibited $\mathrm{Na}^{+} / \mathrm{K}^{+}$ATPase activity in a dose-dependent manner. In most animal cells, $\mathrm{Na}^{+} / \mathrm{K}^{+}$ATPase is responsible for about one-fifth to two-thirds of the cell's energy expenditure [33]. We reasoned that impairment of $\mathrm{Na}^{+} / \mathrm{K}^{+}$ATPase 

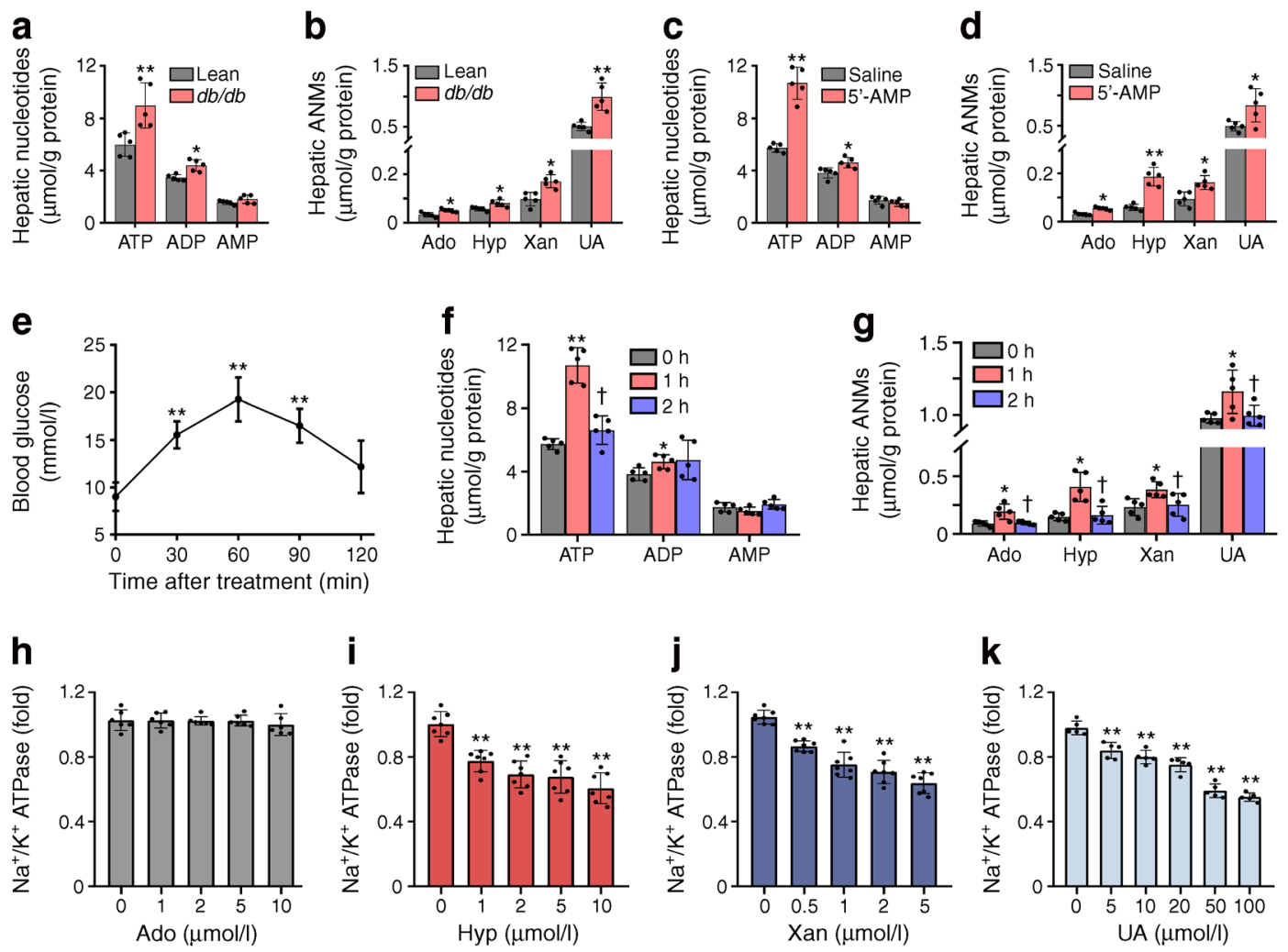

Fig. 2 Hyperglycaemia in obese mice requires accumulation of ATP and ANMs in the liver. (a, b) Quantification of adenine nucleotides (a) and ANMs (b), including adenosine (Ado), hypoxanthine (Hyp), xanthine (Xan) and uric acid (UA), in the liver of $d b / d b$ mice compared with lean mice. In $d b / d b$ mice, ATP and ANMs are elevated in the liver $(n=5)$. (c, d) Quantification of adenine nucleotides (c) and ANMs (d) in the liver of 5'-AMP-treated wild-type mice compared with saline-treated control mice. Similarly, in the 5'-AMP-treated mice, ATP and ANMs are increased in the liver $(n=5)$. (e) The time course of 5'-AMP-induced

activity by ANMs should decrease ATP utilisation and cause a cellular ATP elevation in liver.

Metformin lowers 5'-AMP induced hyperglycaemia and decreases cellular ATP level Metformin, a widely used glucoselowering drug, markedly alleviated 5'-AMP induced hyperglycaemia (Fig. 3a,b). Our analysis showed that metformin decreased 5'-AMP-induced G6Pase and Pepck mRNA expression levels (Fig. 3c). Metformin also reduced 5'AMP-related increases in G6Pase and PEPCK activity (Fig. 3d). Moreover, metformin had no effect on the activity of $\mathrm{Na}^{+} /$ $\mathrm{K}^{+}$ATPase (ESM Fig. 2). HPLC analysis revealed that metformin decreased 5'-AMP-induced ATP elevation but failed to change 5'-AMP-induced ANM accumulation in the liver (Fig. $3 \mathrm{e}, \mathrm{f})$. Similar results were also observed in the metformintreated $d b / d b$ mice (Fig. 3g,h). These results suggest that elevated liver ATP plays a potential role in inducing hyperglycaemia.

ATP is an activator of PTP1B One key question arising from these studies is the biological significance of this abnormal
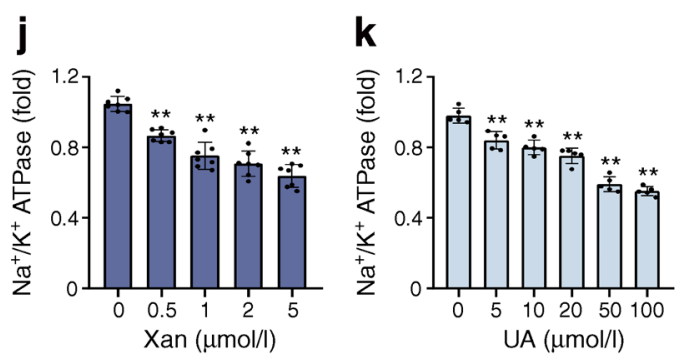

hyperglycaemia in wild-type mice $(n=6)$. ( $\mathbf{f}, \mathbf{g})$ Quantification of adenine nucleotides and ANMs in the livers of $5^{\prime}$-AMP-treated mice compared with saline-treated control mice $(n=5)$. (h-k $) \mathrm{Na}^{+} / \mathrm{K}^{+}$ATPase activity, expressed as fold vs no treatment, was decreased in the presence of ANMs, including Hyp (i; $n=7)$, Xan ( $\mathbf{j} ; n=7)$ and UA $(\mathbf{k} ; n=5)$ but not Ado $(\mathbf{h} ; n=6)$. Data are expressed mean \pm SD. Statistical analysis was performed with Student's $t$ test $(\mathbf{a}-\mathbf{g})$ or one-way ANOVA and Tukey's post hoc test $(\mathbf{h}-\mathbf{k}) ; * p<0.05$ and $* * p<0.01$ compared with the control group; ${ }^{\dagger} p<0.05$ compared with $1 \mathrm{~h}$ group

purinergic metabolism in mice. Perhaps increased ATP level in the liver of obese mice is an important signal for energy utilisation related to glucose metabolism. Our previous work demonstrates that adenosine is an ATP-competitive substrate inhibitor in the phosphorylation of insulin receptors in vitro [34]. We tested whether decreasing cellular adenosine levels alleviated hyperglycaemia in obese $d b / d b$ mice. PEG-ADA was injected intraperitoneally into $d b / d b$ mice to decrease liver adenosine levels. As expected, PEG-ADA obviously decreased cellular adenosine level in mouse livers (ESM Fig. 3). However, PEG-ADA failed to lower blood glucose level in $d b / d b$ mice (ESM Fig. 3), suggesting that adenosine is not a key regulator of blood glucose in vivo. An unexpected finding was that ATP dose-dependently enhanced the activity of PTP1B, a known negative regulator of the insulin signalling pathway (Fig. 4a). To rule out the possibility that this was a non-specific effect that could be triggered by any nucleotide, we added various concentrations of AMP, adenosine and uric acid to mouse liver extracts but none of these molecules increased PTP1B activity (Fig. 4b). A kinetics study of the stimulatory effects of ATP on recombinant PTP1B activity was 

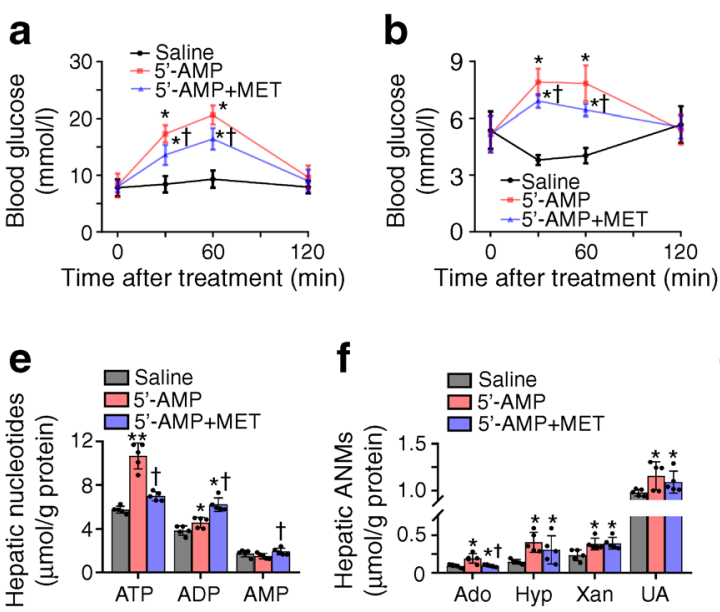

Fig. 3 Metformin reduces hyperglycaemia in 5'-AMP-treated mice and $d b / d b$ mice. (a, b) Metformin (MET) lowers 5'-AMP-induced hyperglycaemia (a) and improves 5'-AMP-induced insulin insensitivity as measured by ITT (b) in wild-type mice. (c) Relative gene expression of G6Pase and Pepck in wild-type mouse liver. Metformin decreased 5'AMP-activated G6Pase and Pepck mRNA levels in wild-type mice. Using $\beta$-actin as internal control, data were analysed according to the $2^{-\Delta \Delta C_{t}}$ method. The expression of all genes is shown as fold change relative to saline-treated control group. (d) Metformin ameliorated 5'-

performed over the substrate concentration range of 0.25 $2 \mathrm{mmol} / \mathrm{l}$ in the presence of 0.2 or $0.4 \mathrm{mmol} / 1$ of ATP. Lineweaver-Burk double-reciprocal plot analysis revealed that ATP increased the maximal PTP1B velocity and decreased the $\mathrm{K}_{\mathrm{m}}$ value. The $\mathrm{K}_{\mathrm{i}}$ value (activation constant) obtained from the Dixon plot was $0.65 \mathrm{mmol} / 1$ (Fig. $4 \mathrm{c}-\mathrm{e}$ ). These studies demonstrate that ATP is an activator of PTP1B and can function as a negative feedback regulator of the insulin signalling pathway.

Metformin is an inhibitor of PTP1B We next investigated whether the stimulatory effect of ATP on PTP1B activity can be inhibited by glucose-lowering drugs such as metformin. Because metformin must be transported into the cell as cationic metformin [35], we first assayed PTP1B activity with cationic metformin in vitro, and found that cationic metformin could effectively inhibit the ATP-stimulated activity of recombinant PTP1B (Fig. 4f,g). Cationic metformin also decreased the activity of the PTP1B in mouse liver extracts in a dosedependent manner (Fig. 4h). In contrast to the effect of ATP, cationic metformin decreased the maximal PTP1B velocity and increased its $\mathrm{K}_{\mathrm{m}}$ value based on Lineweaver-Burk double-reciprocal plot analysis (Fig. $4 \mathrm{i}-\mathrm{k}$ ). The $\mathrm{K}_{\mathrm{i}}$ value (inhibition constant) obtained from the Dixon plot was $0.31 \mathrm{mmol} / \mathrm{l}$. These results indicate that cationic metformin is an inhibitor of PTP1B.

A reciprocal regulation of PTP1B activity by ATP and metformin To further understand the effects of ATP and metformin on PTP1B activity, we investigated the interaction between
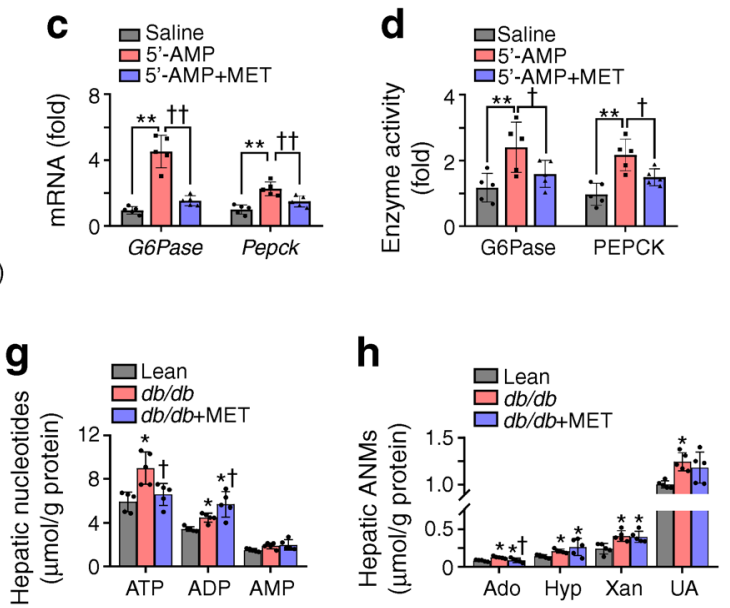

AMP-related increases in G6Pase and PEPCK activity in the liver of wild-type mice. (e, f) Quantification of liver nucleotides and ANMs, including adenosine (Ado), hypoxanthine (Hyp), xanthine (Xan) and uric acid (UA), in 5'-AMP-, metformin- and saline-treated wild-type mice. (g, h) Quantification of liver nucleotides and ANMs in metformin-treated $d b$ / $d b$ mice, saline-treated $d b / d b$ mice and control lean mice $(n=5$ per group). Data are expressed mean $\pm \mathrm{SD} ; * p<0.05$ and $* * p<0.01$ vs saline-treated or lean control group; ${ }^{\dagger} p<0.05$ and ${ }^{\dagger \dagger} p<0.01$ for metformin vs 5 -AMP-treatment or $d b / d b$ group (Student's $t$ test)

PTP1B and ATP or metformin by MST assay. The fluorescence intensity of labelled PTP1B detected by the MST reader did not vary until micromolar levels of ATP or cationic metformin were present (Fig. 5a-d). This suggests a lower affinity between ATP and PTP1B. Similarly, metformin displayed a lower affinity for PTP1B. The sigmoidal binding curve observed in the presence of ATP was different from that obtained with metformin. The different shape of the fit curves can be related to $\mathrm{pH}$-dependent thermophoresis type [36]. Next, we observed that the binding curve obtained at acidic $\mathrm{pH}$ values was equal to that following addition of ATP and that the binding curve obtained at basic $\mathrm{pH}$ values was similar to that following addition of metformin (Fig. 5e-h). These data suggest that ATP and metformin might influence $\mathrm{pH}$ value, resulting in the variation in fluorescence intensity under the MST reader. Indeed, a precise $\mathrm{pH}$ assay revealed that ATP and metformin caused a reciprocal change in the $\mathrm{pH}$ of assay buffers (Fig. 5i,j) and that PTP1B activity was strongly dependent on $\mathrm{pH}$ (Fig. 5k).

\section{Extracellular nucleotides and metformin regulate $\mathrm{pH}_{\mathrm{i}}$ homeo-} stasis in hepatocytes It is known that uptake of metformin hydrochloride into hepatocytes is catalysed by the organic cation transporter-1 (OCT1) [35]. Being positively charged, the cation metformin accumulates in cells [21]. We investigated whether exogenous metformin hydrochloride and nucleotides induced intracellular $\mathrm{pH}$ changes in cultured hepatocytes. After addition of metformin hydrochloride and ATP, hepatic $\mathrm{pH}_{\mathrm{i}}$ was measured from green (BCECF) images taken at $490 \mathrm{~nm}$ and $440 \mathrm{~nm}$ excitation wavelengths. Under control 
a

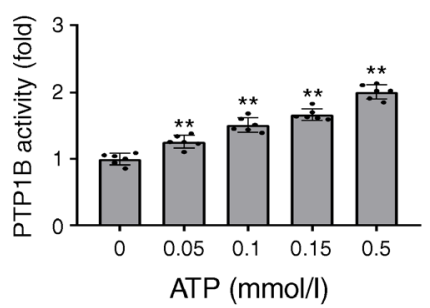

b

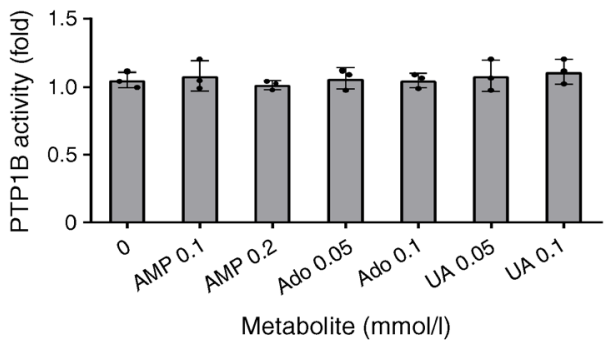

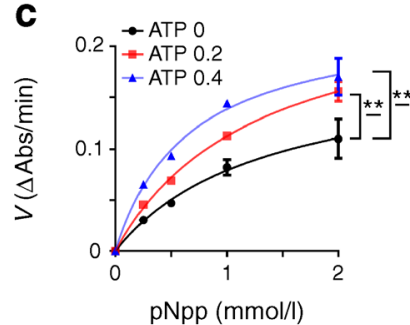

f

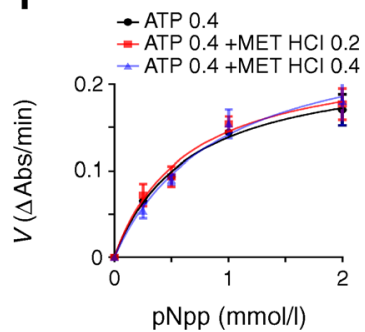

i

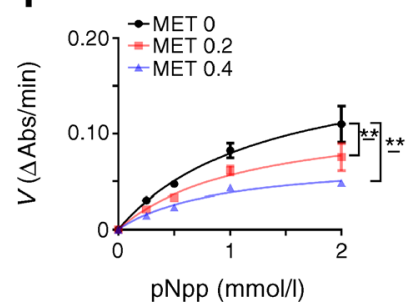

d

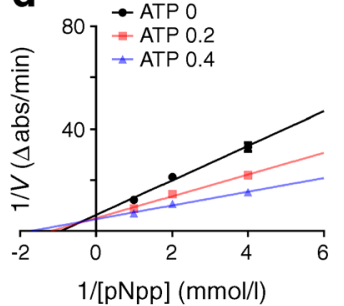

g
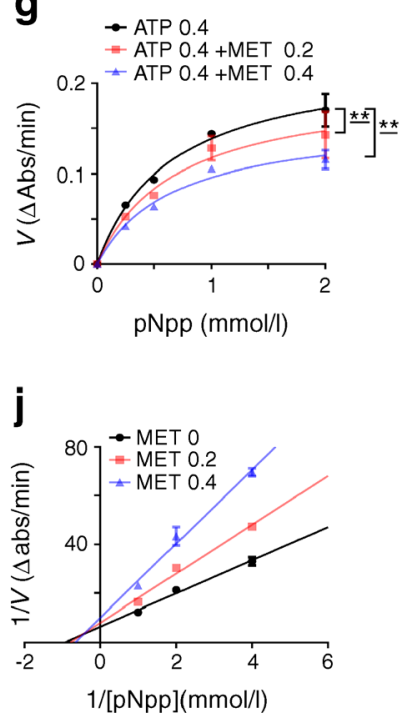

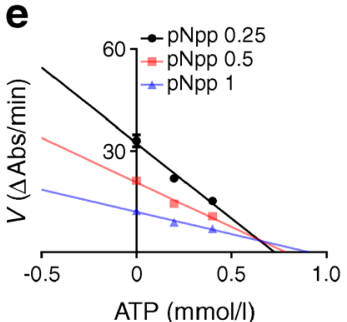

h
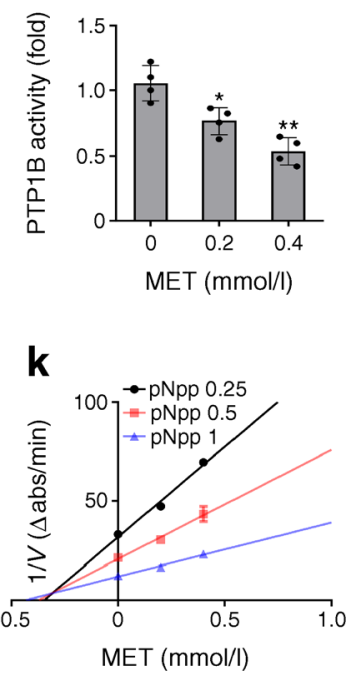

Fig. 4 Reciprocal regulation of hepatic PTP1B activity by 5'-AMP and metformin. (a) ATP increased PTP1B activity in liver extracts from C57BL $/ 6$ mice $(n=6)$. (b) ATP metabolites, including 5'-AMP (AMP), adenosine (Ado) and uric acid (UA), had no obvious effect on PTP1B activity in liver extracts $(n=3)$. (c-e) Recombinant PTP1B stimulation was analysed in the presence of different concentrations of ATP $(\mathrm{mmol} / \mathrm{l})$ $(n=3)$. ATP stimulated the activity of PTP1B $(\mathbf{c})$. Lineweaver-Burk plot for PTP1B stimulation by ATP indicated that ATP increased the $V_{\max }$ of PTP1B and decreased the $K_{\mathrm{m}}$ of PTP1B substrate (d). The activation constant was determined by interpretation of the Dixon plot (e). (f, $\mathbf{g})$ Cationic metformin (MET) (mmol/l) (g), not metformin hydrochloride $(\mathrm{MET} \mathrm{HCl})(\mathrm{mmol} / \mathrm{l})(\mathbf{f})$, inhibits ATP-stimulated $(\mathrm{mmol} / \mathrm{l})$ recombinant PTP1B activity $(n=3)$. (h) Cationic metformin inhibits PTP1B activity in a dose-dependent manner in liver extracts $(n=4)$. (i-k) Recombinant

conditions, the typical effect of extracellular $5^{\prime}-\mathrm{AMP}$ on $\mathrm{pH}_{\mathrm{i}}$ in hepatocytes is illustrated in Fig. 6a. Exposure to 5'-AMP resulted in a rapid decrease of $0.45 \pm 0.08 \mathrm{pH}$ units; lower concentrations of 5 -AMP $(10 \mu \mathrm{mol} / 1$ and $100 \mu \mathrm{mol} / \mathrm{l})$ also
PTP1B stimulation was analysed in the presence of different concentrations of metformin $(\mathrm{mmol} / \mathrm{l})(n=3)$. Metformin inhibited the activity of PTP1B (i). Lineweaver-Burk plots for recombinant PTP1B inhibition by metformin indicates that metformin decreased the $V_{\max }$ of PTP1B and increased the $K_{\mathrm{m}}$ value for the PTP1B substrate (j). The inhibition constant was determined by interpretation of the Dixon plots (k). The range for substrate $\mathrm{pNpp}$ concentrations is $0.25-2 \mathrm{mmol} / \mathrm{l}$ in $(\mathbf{c}, \mathbf{f}, \mathbf{g}, \mathbf{i})$ and $0.25-1 \mathrm{mmol} / 1$ in $(\mathbf{d}, \mathbf{e}, \mathbf{j}, \mathbf{k})$. The results represent the mean $\pm \mathrm{SD}$. Data in $(\mathbf{a}, \mathbf{b}, \mathbf{h})$ are expressed as fold vs $0 \mathrm{mmol} / \mathrm{l}$ metformin. Statistical analysis was performed by one-way ANOVA followed by Tukey's post hoc test $(\mathbf{a}, \mathbf{b}, \mathbf{h})$ or by two-way ANOVA followed by Tukey's post hoc test $(\mathbf{c}, \mathbf{f}, \mathbf{g}, \mathbf{i}) . * p<0.05$ and $* * p<0.01$ vs control group. $\Delta$ Abs, change in absorbance; $\mathrm{pNpp}$, p-nitrophenyl phosphate

reduced intracellular $\mathrm{pH}$ to different degrees (ESM Fig. 4). Extracellular metformin hydrochloride caused $\mathrm{pH}_{\mathrm{i}}$ to rise (Fig. 6b). Cytoplasmic pH was stable at 7.2-7.4 under the control experimental conditions but promptly became acidic 

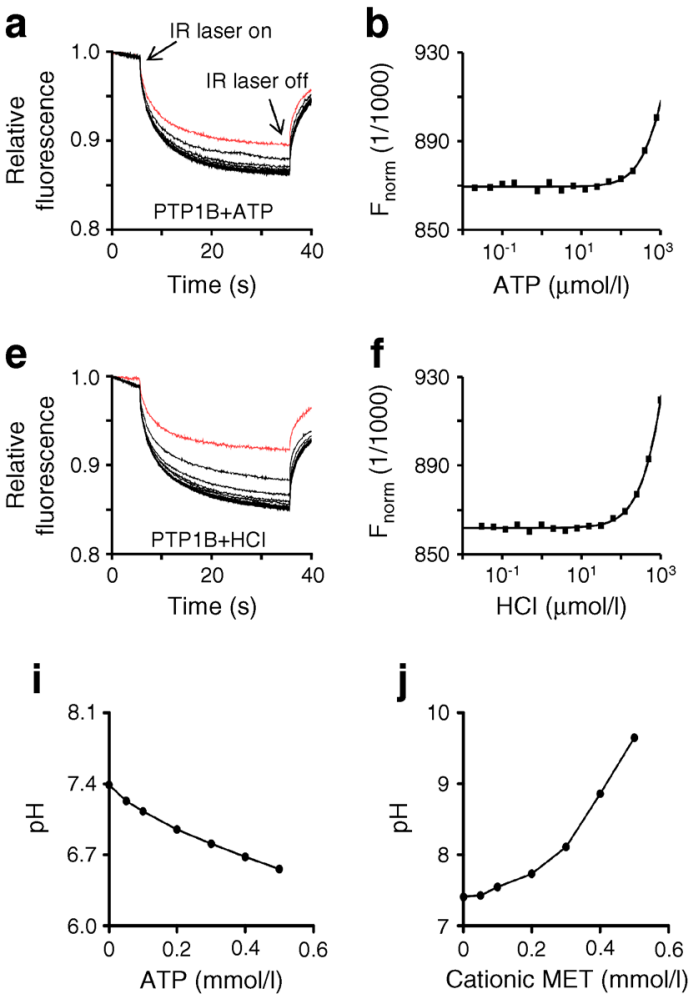

Fig. 5 Interaction between ATP, metformin and PTP1B. (a-d) MST data analysis of ATP $(\mathbf{a}, \mathbf{b})$ and cationic metformin (MET) (c, d) with PTP1B. The binding curve observed in the presence of ATP was different from that obtained with metformin. (e-h) MST data analysis of $\mathrm{HCl}(\mathbf{e}, \mathbf{f})$ and $\mathrm{NaOH}(\mathbf{g}, \mathbf{h})$ with fluorescently labelled recombinant PTP1B. The binding curves in (e) and (g) were similar to those observed for ATP (a) and cationic metformin (c), respectively. Traces in $(\mathbf{a}),(\mathbf{c}),(\mathbf{e})$ and $(\mathbf{g})$ represented the relative fluorescence over time of different ligand concentrations. The red traces correspond to the point of highest concentration

(6.7-6.9) after 5'-AMP treatment. On the contrary, treating cells with metformin hydrochloride increased the cytoplasmic $\mathrm{pH}$ to 7.5-7.8. Representative wide-field fluorescence images of the BCECF green fluorescence excited at two wavelengths, together with a pseudocoloured ratio image map of cell $\mathrm{pH}$, are shown in Fig. 6c. Next, we found that ANMs, including hypoxanthine, xanthine and uric acid, significantly reduced $\mathrm{Na}^{+} / \mathrm{H}^{+}$exchanger activity in AML12 cells (ESM Fig. 5), indicating that the ANMs caused deregulation of $\mathrm{pH}_{\mathrm{i}}$. A decreased intracellular $\mathrm{Na}^{+}$level was observed in 5'-AMP-treated cells (ESM Fig. 6). The ANMs had no effects on liver vacuolar $\mathrm{H}^{+}$ATPase activity (ESM Fig. 7). Together, our studies suggest that accumulated ANMs inhibit $\mathrm{Na}^{+} / \mathrm{H}^{+}$exchanger activity and that ATP and metformin, as proton donors and receptors, reciprocally regulate $\mathrm{pH}_{\mathrm{i}}$ homeostasis in liver cells (Fig. 6d).

pAMP was elevated in people with type 2 diabetes To further investigate the potential association between elevated pAMP and type 2 diabetes, we analysed the pAMP level in individuals with type 2 diabetes. The clinical characteristics of the
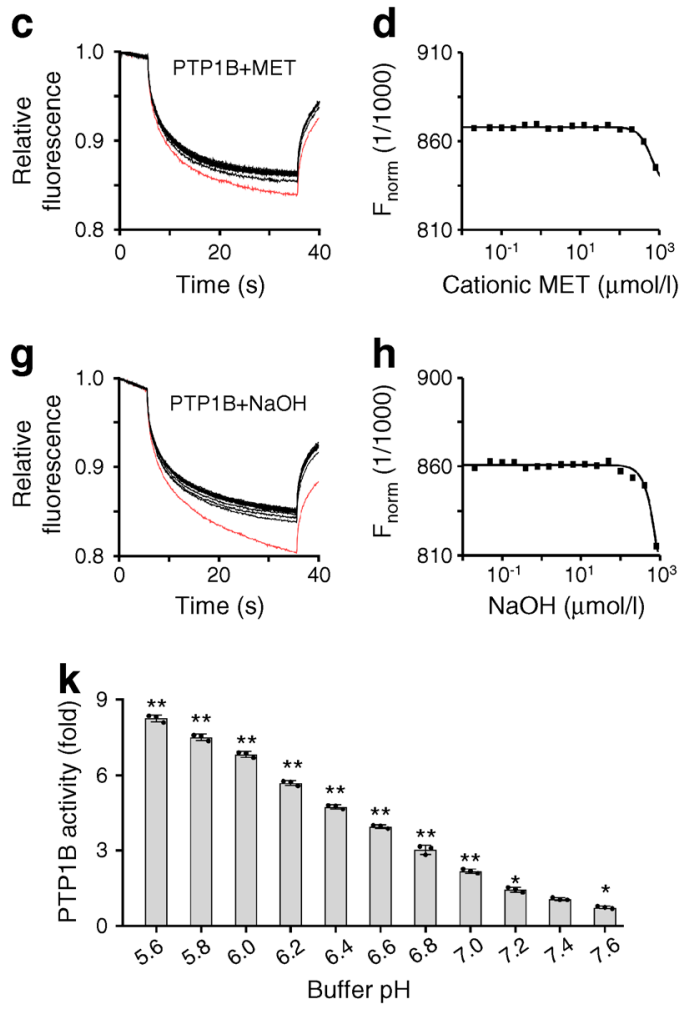

shown in (b), (d), (f) and (h), respectively. The $F_{\text {norm }}$ value was calculated by taking the ratio between the relative fluorescence after heating (infrared [IR] laser off) and before heating (IR laser on), as shown for (a). (i, j) The effects of ATP (i) and metformin (j) on pH of PTP1B assay buffers. (k) Effects of buffer $\mathrm{pH}$ on recombinant PTP1B activity, expressed as activity relative to activity at $\mathrm{pH}$ 7.4. For $(\mathbf{a}-\mathbf{j})$, results are representative of three independent experiments. Data in $(\mathbf{k})$ are shown as mean $\pm \mathrm{SD}$ of three samples; $* p<0.05$ and $* * p<0.01$ vs activity at $\mathrm{pH} 7.4$ (one-way ANOVA followed by Tukey's post hoc test)

participants are shown in Table 1. Twenty-five participants with type 2 diabetes and 21 non-diabetic healthy control individuals participated in the study. The control group had similar age and sex distribution to the diabetes patients. Diabetic individuals had higher BMI and $\mathrm{HbA}_{1 \mathrm{c}}$. As shown in Fig. 7a, although the absolute level of pAMP in humans was far less than that in mice, it was still significantly elevated in diabetic individuals $(45.2 \pm 22.7 \mathrm{nmol} / \mathrm{l})$ compared with non-diabetic individuals $(3.1 \pm 1.9 \mathrm{nmol} / \mathrm{l})$. Fasting plasma glucose and insulin concentrations were significantly increased in the diabetic individuals (Fig. 7b,c). Together, these observations confirm that elevated pAMP is a universal marker in type 2 diabetes.

\section{Discussion}

Our results show that ATP and ANM accumulation in liver cells promote hyperglycaemia in obesity-related type 2 diabetes. Sustained hyperglycaemia impairs insulin-stimulated glucose utilisation in the skeletal muscle, a phenomenon that is referred 
a
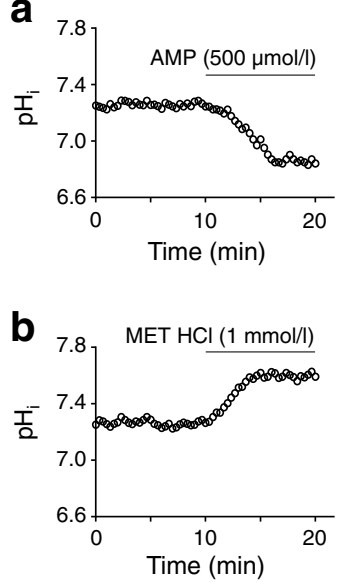

C
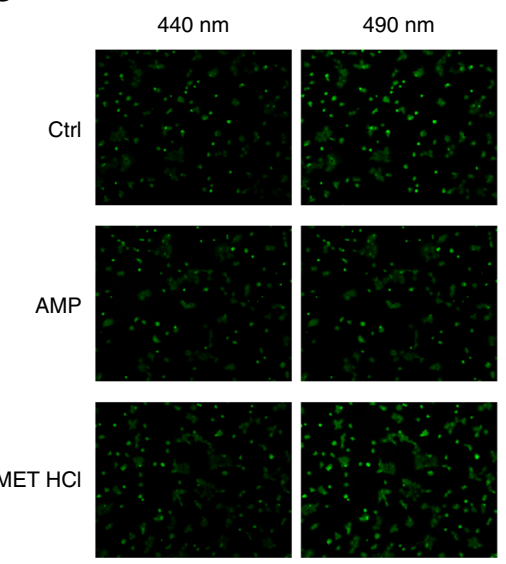

Ratio image

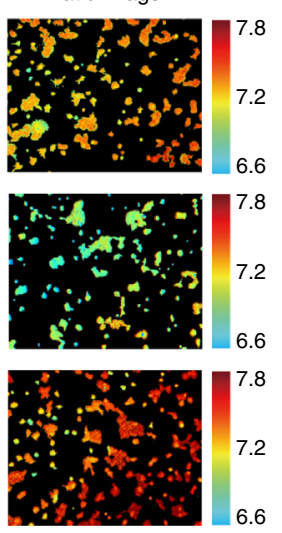

d

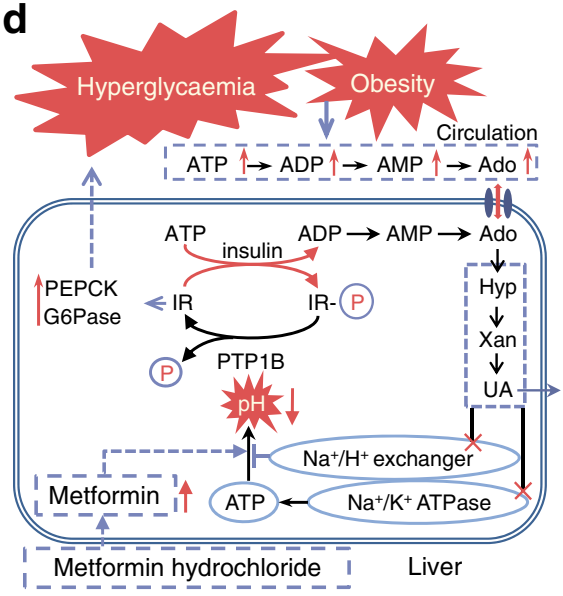

Fig. 6 Effects of exogenous $5^{\prime}$-AMP and metformin on $\mathrm{pH}_{\mathrm{i}}$ of AML12 hepatocytes. (a) 5'-AMP produced a rapid decrease in $\mathrm{pH}_{\mathrm{i}}$. (b) Extracellular metformin hydrochloride (MET $\mathrm{HCl}$ increased $\mathrm{pH}_{\mathrm{i}}$. (c) Fluorescence images of BCECF-stained AML12 hepatocytes taken at $440 \mathrm{~nm}$ and $490 \mathrm{~nm}$ excitation wavelengths. The pseudocoloured ratio image shows a spatial map of $\mathrm{pH}_{\mathrm{i}}$ (colour $\mathrm{pH}$ scale to the right). The images show the difference of $\mathrm{pHi}$ between cells treated with 5 -AMP or metformin hydrochloride and the control group (Ctrl). (d) Model showing the pivotal role of cellular $\mathrm{pH}$ in regulation of insulin negative

to clinically as glucose toxicity. Although insulin resistance is thought to arise during the early stage of type 2 diabetes, this process often remains undetectable. In contrast to hyperglycaemia, insulin resistance is a well-evolved protective mechanism during acute illness that helps conserve the brain's glucose supply by preventing muscles from taking up excessive glucose [37]. Thus, a better understanding of the pathological causes of hyperglycaemia in type 2 diabetes is essential for more rational and appropriate treatment of diabetic individuals.

Release of NEFA from adipose tissue and increased levels of ANMs such as uric acid are important hallmarks of insulin resistance and type 2 diabetes $[38,39]$. NEFA-induced nucleotide release from vascular endothelial cells is important for accumulation of ANMs in organs such as liver and skeletal muscle [22]. Inhibiting ATP release by drugs such as glibenclamide (known as a

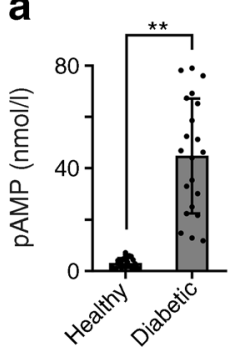

b

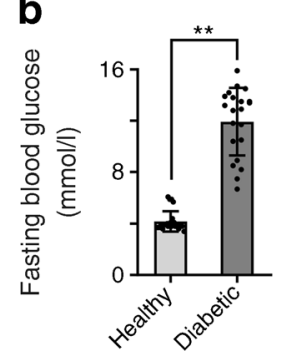

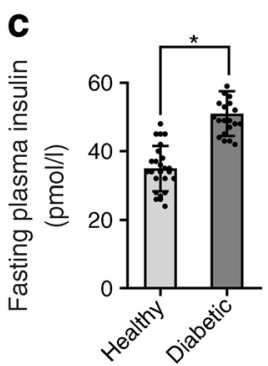

Fig. 7 pAMP was elevated in individuals with type 2 diabetes. Quantification of pAMP by HPLC analysis (a), fasting blood glucose (b) and fasting plasma insulin (c) in individuals with type 2 diabetes. The diabetic individuals had elevated pAMP levels compared with a control group of healthy individuals. Values are shown as mean $\pm \mathrm{SD}$, $n=21$ (healthy) and $n=25$ (diabetic). $* p<0.05$ and $* * p<0.01$ vs healthy individuals (Student's $t$ test) signalling of PTP1B involving ATP and its metabolites. NEFA-related increase in intracellular ANM accumulation inhibits $\mathrm{Na}^{+} / \mathrm{K}^{+}$ATPase and $\mathrm{Na}^{+} / \mathrm{H}^{+}$exchanger activity, resulting in cellular ATP elevation and $\mathrm{pH}_{\mathrm{i}}$ deregulation. Cellular ATP donates $\mathrm{H}^{+}$, directly causing cytoplasmic acidification, and activates the insulin negative regulatory pathway of PTP1B, increasing hepatic glucose production (via PEPCK and G6Pase). Metformin elevates hepatic $\mathrm{pH}_{\mathrm{i}}$ and substantially increases insulin sensitivity. Ado, adenosine; Hyp, hypoxanthine; IR, insulin receptor; $\mathrm{P}$, phosphate; UA, uric acid; Xan, xanthine

glyburide in the USA and Canada) improves insulin resistance and decreases blood glucose levels in type 2 diabetes [40]. It is reported that insulin resistance develops within hours of an acute increase in plasma NEFA levels in humans [41], and hepatic inflammation has been suggested to be a consequence (rather than a cause) of insulin resistance [42]. Thus, elevated levels of plasma nucleotides could serve as an early signal for diabetes. Different from diabetic mice, non-diabetic obese mice did not display a significant change in pAMP level. Non-diabetic $o b / o b$ mice had higher NEFA levels compared with lean mice but the levels were much lower than in diabetic $d b / d b$ mice [43]. Thus, levels of nucleotides released by NEFA in these obese mice might be less than in diabetic mice. Ecto-5'-nucleotidase in circulation converts nucleotides to adenosine and is rapidly transported into cells [44]. The intracellular effect of plasma nucleotides is likely mediated through increased cellular adenosine levels. Indeed, adenosine is an inhibitor of insulin signalling [34]. However, elevation of adenosine alone causes insulin resistance but not hyperglycaemia, as observed in $o b / o b$ and HFD-fed mice. Similarly, a low dose of 5'-AMP induced insulin resistance rather than hyperglycaemia. With increased plasma nucleotides, liver accumulates ANMs and hyperglycaemia occurs. ANMs are independent inhibitors of $\mathrm{Na}^{+} / \mathrm{K}^{+}$ATPase; this inhibition inevitably reduces ATP utilisation, resulting in elevation of hepatic ATP. Cellular ATP elevations were also observed in diabetic or $5^{\prime}$ AMP-treated mouse kidney but not skeletal muscle (ESM Fig. 8). On the other hand, ANMs also inhibited activity of the $\mathrm{Na}^{+} /$ $\mathrm{H}^{+}$exchanger, which is crucial in maintaining homeostasis of $\mathrm{pH}_{\mathrm{i}}$ and sodium [45]. Thus, ANM accumulation could cause a deregulation of $\mathrm{pH}_{\mathrm{i}}$. 
Coincidentally, $\mathrm{pH}$ is an important regulatory factor for PTP1B [46], which negatively regulates insulin signalling by dephosphorylating tyrosine residues on insulin receptors and IRS proteins [14]. Loss of PTP1B function in mice is associated with increased insulin sensitivity [47]. In our liver cell extracts or recombinant PTP1B enzyme assay system, ATP enhanced PTP1B activity in a dose-dependent manner; metformin (but not metformin hydrochloride) caused a dose-dependent inhibition of PTP1B activity. ATP and metformin acted as an activator and an inhibitor of PTP1B, respectively, causing a reciprocal change in the $\mathrm{pH}$ of PTP1B assay buffer. This phenomenon was further proved by binding assay. Metformin, an oral glucose-lowering agent that is widely used in the management of non-insulin-dependent diabetes mellitus [48], significantly improved nucleotide-induced insulin resistance and hyperglycaemia. Metformin is primarily excreted unchanged in the urine, with negligible metabolism [49], and is a substrate for OCT1 [39], which is responsible for the hepatic uptake of metformin. Thus, metformin hydrochloride must be transported into cells in the form of cationic metformin. Indeed, the cation metformin is observed to accumulate in cells [21]. Metformin is a stronger base than most other basic drugs [49]. Therefore, it is believed that hepatic uptake of cationic metformin is an essential step in elevating hepatic cell $\mathrm{pH}$, as well as the occurrence of PTP1B-inhibiting effects such as improved insulin sensitivity.

Thus, our studies uncover a novel key step in the pathogenesis of diabetes-related excessive hepatic glucose production and reveal an emerging role for adenine nucleotides that permits hyperglycaemia to occur in obese mice. As illustrated in Fig. 6d, NEFA-related increase in intracellular ANM accumulation inhibits $\mathrm{Na}^{+} / \mathrm{K}^{+}$ATPase and $\mathrm{Na}^{+} / \mathrm{H}^{+}$exchanger activity, resulting in cellular ATP elevation and $\mathrm{pH}_{\mathrm{i}}$ deregulation. Cellular ATP, as an $\mathrm{H}^{+}$donor, directly causes cytoplasmic acidification and activates the insulin negative regulatory pathway of PTP1B, increasing hepatic glucose production. A causal role of cellular $\mathrm{pH}$ homeostasis is shown by the observation that metforminelevated hepatic $\mathrm{pH}_{\mathrm{i}}$ substantially increases insulin sensitivity. More effective $\mathrm{pH}$ regulatory agents under development for use in treating obesity-induced insulin resistance may prove worthy of investigation.

Data availability Data are available upon request from the corresponding author.

Funding This work was supported by a grant from the National Natural Science Foundation of China (nos 31671220, 31861163004).

Duality of interest The authors declare that there is no duality of interest associated with this manuscript.

Contribution statement $\mathrm{XY}, \mathrm{YZ}$ and QS performed the experiments. XY, YZ, QS, YXY, YG, WHG and JHL analysed the data, interpreted the results, and reviewed and edited the manuscript. XX, DW and SMW contributed to the discussion, provided advice on experimental design and reviewed the manuscript. JFZ designed the study and wrote the manuscript. All authors approved the final version of this manuscript. JFZ is the guarantor of this work.

\section{References}

1. Cahill GF Jr (2012) Starvation in man. N Engl J Med 282:668-675

2. DeFronzo RA, Ferrannini E, Simonson DC (1989) Fasting hyperglycemia in non-insulin-dependent diabetes mellitus: contributions of excessive hepatic glucose production and impaired tissue glucose uptake. Metabolism 38(4):387-395. https://doi.org/10.1016/ 0026-0495(89)90129-7

3. Kraegen EW, Clark PW, Jenkins AB, Daley EA, Chisholm DJ, Storlien LH (1991) Development of muscle insulin resistance after liver insulin resistance in high-fat-fed rats. Diabetes 40(11):13971403. https://doi.org/10.2337/diab.40.11.1397

4. Kahn SE, Hull RL, Utzschneider KM (2006) Mechanisms linking obesity to insulin resistance and type 2 diabetes. Nature 444(7121): 840-846. https://doi.org/10.1038/nature05482

5. Halaas JL, Gajiwala KS, Maffei M et al (1995) Weight-reducing effects of the plasma protein encoded by the obese gene. Science 269(5223):543-546. https://doi.org/10.1126/science.7624777

6. Srinivasan K, Ramarao P (2007) Animal models in type 2 diabetes research: an overview. Indian J Med Res 125:451-472

7. Aasum E, Hafstad AD, Severson DL, Larsen TS (2003) Agedependent changes in metabolism, contractile function, and ischemic sensitivity in hearts from $d b / d b$ mice. Diabetes 52(2):434-441. https://doi.org/10.2337/diabetes.52.2.434

8. Hotamisligil GS (1999) Mechanisms of TNF- $\alpha$-induced insulin resistance. Diabetes 107:119-125

9. Coleman DL (1978) Obese and diabetes: two mutant genes causing diabetes-obesity syndromes in mice. Diabetologia 14(3):141-148. https://doi.org/10.1007/BF00429772

10. Tahara A, Matsuyama-Yokono A, Shibasaki M (2011) Effects of antidiabetic drugs in high-fat diet and streptozotocin-nicotinamideinduced type 2 diabetic mice. Eur J Pharmacol 655(1-3):108-116. https://doi.org/10.1016/j.ejphar.2011.01.015

11. Taylor SI, Accili D, Imai Y (1994) Insulin resistance or insulin deficiency. Which is the primary cause of NIDDM? Diabetes 43(6):735-740. https://doi.org/10.2337/diab.43.6.735

12. White MG, Shaw JA, Taylor R (1978) Type 2 diabetes: the pathologic basis of reversible $\beta$-cell dysfunction. Diabetes Care 39: 2080-2088

13. Kashyap SR, Defronzo RA (2007) The insulin resistance syndrome: physiological considerations. Diabetes Vasc Dis Res 4(1): 13-19. https://doi.org/10.3132/dvdr.2007.001

14. Egawa K, Maegawa H, Shimizu S et al (2001) Protein-tyrosine phosphatase-1B negatively regulates insulin signaling in 16 myocytes and Fao hepatoma cells. J Biol Chem 276(13):1020710211. https://doi.org/10.1074/jbc.M009489200

15. Vicario P, Brady EJ, Slater EE, Saperstein R (1987) Insulin receptor tyrosine kinase activity is unaltered in ob/ob and $\mathrm{db} / \mathrm{db}$ mouse skeletal muscle membranes. Life Sci 41(10):1233-1241. https://doi. org/10.1016/0024-3205(87)90201-3

16. Zinker BA, Rondinone CM, Trevillyan JM et al (2002) PTP1B antisense oligonucleotide lowers PTP1B protein, normalizes blood glucose, and improves insulin sensitivity in diabetic mice. Proc Natl Acad Sci U S A 99(17):11357-11362. https://doi.org/10.1073/ pnas. 142298199

17. Argaud D, Roth H, Wiernsperger N, Leverve XM (1993) Metformin decreases gluconeogenesis by enhancing the pyruvate kinase flux in isolated rat hepatocytes. Eur J Biochem 213(3): 1341-1348. https://doi.org/10.1111/j.1432-1033.1993.tb17886.x 
18. Gunton JE, Delhanty PJ, Takahashi S, Baxter RC (2003) Metformin rapidly increases insulin receptor activation in human liver and signals preferentially through insulin-receptor substrate-2. J Clin Endocrinol Metab 88(3):1323-1332. https://doi.org/10.1210/jc. 2002-021394

19. Lee JO, Lee SK, Jung JH et al (2011) Metformin induces Rab4 through AMPK and modulates GLUT4 translocation in skeletal muscle cells. J Cell Physiol 226(4):974-981. https://doi.org/10. $1002 /$ jcp. 22410

20. Zhou G, Myers R, Li Y et al (2001) Role of AMP-activated protein kinase in mechanism of metformin action. J Clin Invest 108(8): 1167-1174. https://doi.org/10.1172/JCI13505

21. Owen MR, Doran E, Halestrap AP (2000) Evidence that metformin exerts its anti-diabetic effects through inhibition of complex 1 of the mitochondrial respiratory chain. Biochem J 34:607-614

22. Zhang Y, Wang Z, Zhao Y et al (2012) The plasma 5'-AMP acts as a potential upstream regulator of hyperglycemia in type 2 diabetic mice. Am J Physiol Endocrinol Metab 302(3):E325-E333. https:// doi.org/10.1152/ajpendo.00424.2011

23. Knudsen TB, Winters RS, Otey SK et al (1992) Effects of (R)deoxycoformycin (pentostatin) on intrauterine nucleoside catabolism and embryo viability in the pregnant mouse. Teratology 45(1):91-103. https://doi.org/10.1002/tera.1420450109

24. Ramsey KM, Yoshino J, Brace CS et al (2009) Circadian clock feedback cycle through NAMPT-mediated NAD+ biosynthesis. Science 324(5927):651-654. https://doi.org/10.1126/science.1171641

25. Smolenski RT, Lachno DR, Ledingham SJ, Yacoub MH (1990) Determination of sixteen nucleotides, nucleosides and bases using high-performance liquid chromatography and its application to the study of purine metabolism in hearts for transplantation. J Chromatogr 527:414-420. https://doi.org/10.1016/S03784347(00)82125-8

26. Santra A, Maiti A, Das S, Lahiri S, Charkaborty SK, Mazumder DN (2000) Hepatic damage caused by chronic arsenic toxicity in experimental animals. J Toxicol Clin Toxicol 38(4):395-405. https://doi. org/10.1081/CLT-100100949

27. Tsakiris S, Deliconstantinos G (1984) Influence of phosphatidylserine on $\left(\mathrm{Na}^{+}+\mathrm{K}^{+}\right)$-stimulated ATPase and acetylcholinesterase activities of dog brain synaptosomal plasma membranes. Biochem J 220(1):301-307. https://doi.org/10.1042/ bj2200301

28. Minassian C, Daniele N, Bordet JC, Zitoun C, Mithieux G (1995) Liver glucose-6-phosphatase activity is inhibited by refeeding in rats. J Nutr 125(11):2727-2732. https://doi.org/10.1093/jn/125.11.2727

29. Petrescu I, Bojan O, Saied M, Bârzu O, Schmidt F, Kühnle HF (1979) Determination of phosphoenolpyruvate carboxykinase activity with deoxyguanosine $5^{\prime}$-diphosphate as nucleotide substrate. Anal Biochem 96(2):279-281. https://doi.org/10.1016/00032697(79)90582-7

30. Wang CD, Teng BS, He YM et al (2012) Effect of a novel proteoglycan PTP1B inhibitor from Ganoderma lucidum on the amelioration of hyperglycaemia and dyslipidaemia in $d b / d b$ mice. Br $\mathbf{J}$ Nutr 108(11):2014-2025. https://doi.org/10.1017/ S0007114512000153

31. Timofeeva OA, Chasovskikh S, Lonskaya I et al (2012) Mechanisms of unphosphorylated STAT3 transcription factor binding to DNA. J Biol Chem 287(17):14192-14200. https://doi.org/ 10.1074/jbc.M111.323899

32. Humez S, Monet M, van Coppenolle F, Delcourt P, Prevarskaya N (2004) The role of intracellular $\mathrm{pH}$ in cell growth arrest induced by ATP. Am J Physiol Cell Physiol 287(6):C1733-C1746. https://doi. org/10.1152/ajpcell.00578.2003

33. Howarth C, Gleeson P, Attwell D (2012) Updated energy budgets for neural computation in the neocortex and cerebellum. J Cereb
Blood Flow Metab 32(7):1222-1232. https://doi.org/10.1038/ jcbfm. 2012.35

34. Xia L, Wang Z, Zhang Y et al (2015) Reciprocal regulation of insulin and plasma 5'-AMP in glucose homeostasis in mice. J Endocrinol 224(3):225-234. https://doi.org/10.1530/JOE-14-0501

35. Wang DS, Jonker JW, Kato Y, Kusuhara H, Schinkel AH, Sugiyama Y (2002) Involvement of organic cation transporter 1 in hepatic and intestinal distribution of metformin. J Pharmacol Exp Ther 302(2):510 515. https://doi.org/10.1124/jpet.102.034140

36. Sénéchal F, L'Enfant M, Domon JM et al (2015) Tuning of pectin methylesterification: pectin methylesterase inhibitor 7 modulates the processive activity of co-expressed pectin methylesterase 3 in a pH-dependent manner. J Biol Chem 290(38):23320-23335. https://doi.org/10.1074/jbc.M115.639534

37. Wang G (2014) Raison d être of insulin resistance: the adjustable threshold hypothesis. J R Soc Interface 11(101):2014089220140892. https://doi.org/10.1098/rsif.2014.0892

38. Herman JB, Goldbourt U (1982) Uric acid and diabetes: observations in a population study. Lancet 320(8292):240-243. https://doi. org/10.1016/S0140-6736(82)90324-5

39. Dehghan A, van Hoek M, Sijbrands EJ, Hofman A, Witteman JC (2008) High serum uric acid as a novel risk factor for type 2 diabetes. Diabetes Care 31(2):361-362. https://doi.org/10.2337/dc07-1276

40. Rains SG, Wilson GA, Richmond W, Elkeles RS (1998) The effect of glibenclamide and metformin on serum lipoproteins in type 2 diabetes. Diabet Med 5:653-658

41. Roden M, Price TB, Perseghin G et al (1996) Mechanism of free fatty acid-induced insulin resistance in humans. J Clin Invest 97(12):2859-2865. https://doi.org/10.1172/JCI118742

42. Funke A, Schreurs M, Aparicio-Vergara M et al (2014) Cholesterolinduced hepatic inflammation does not contribute to the development of insulin resistance in male LDL receptor knockout mice. Atherosclerosis 232(2):390-396. https://doi.org/10.1016/j. atherosclerosis.2013.11.074

43. Nowicki M, Kosacka J, Serke H, Blüher M, Spanel-Borowski K (2012) Altered sciatic nerve fiber morphology and endoneural microvessels in mouse models relevant for obesity, peripheral diabetic polyneuropathy, and the metabolic syndrome. J Neurosci Res 90(1):122-131. https://doi.org/10.1002/jnr.22728

44. Zimmermann H (1992) 5'-Nucleotidase: molecular structure and functional aspects. Biochem J 285(2):345-365. https://doi.org/10. 1042/bj2850345

45. Grinstein S, Rothstein A (1986) Mechanisms of regulation of the $\mathrm{Na}+\mathrm{H}+$ exchanger. J Membr Biol 90(1):1-12. https://doi.org/10. 1007/BF01869680

46. Peters GH, Branner S, Møller KB, Andersen JN, Møller NP (2003) Enzyme kinetic characterization of protein tyrosine phosphatases. Biochimie 85(5):527-534. https://doi.org/10.1016/S0300-9084(03) 00036-1

47. Klaman LD, Boss O, Peroni OD et al (2000) Increased energy expenditure, decreased adiposity, and tissue-specific insulin sensitivity in protein-tyrosine phosphatase 1B-deficient mice. Mol Cell Biol 20(15):5479-5489. https://doi.org/10.1128/MCB.20.15.54795489.2000

48. Stumvoll M, Nurjhan N, Perriello G, Dailey G, Gerich JE (1995) Metabolic effects of metformin in non-insulin-dependent diabetes mellitus. N Engl J Med 333(9):550-554. https://doi.org/10.1056/ NEJM199508313330903

49. Scheen AJ (1996) Clinical pharmacokinetics of metformin. Clin Pharmacokinet 30(5):359-371. https://doi.org/10.2165/00003088199630050-00003

Publisher's note Springer Nature remains neutral with regard to jurisdictional claims in published maps and institutional affiliations. 